Vol. 8 No. 2 September 2020, Hal. 378-386

\title{
STRATEGI PEMERINTAH DAERAH DALAM PELAKSANAAN PROGRAM PEMBERDAYAAN GOTONG ROYONG DI DESA KELANIR KECAMATAN SETELUK KABUPATEN SUMBAWA BARAT TAHUN 2017
}

\author{
Yudhi Lestanata, a1 ${ }^{\text {, Ilham Zitri }}{ }^{\text {b2 }}$, Susiana ${ }^{\mathrm{c} 3}$ \\ ${ }^{a}$ Universitas Muhammadiyah Mataram \\ ${ }^{\mathrm{b}}$ Universitas Muhammadiyah Mataram \\ 'Universitas Muhammadiyah Mataram \\ 1yudhi.lestanata@ummatac.id , ${ }^{2}$, Ilham.Zitri@ummat.ac.id, ${ }^{3}$ susiana08@gmail.com
}

\section{INFO ARTIKEL}

\section{Riwayat Artikel:}

Diterima: $17-08-2020$

Disetujui: 25-08-2020

\section{Kata Kunci: \\ 1. Strategi \\ 2.Pemberdayaan \\ Masyarakat \\ 3. PDPGR}

Keyword:

\section{Strategy \\ 2. Community development \\ 3. PDPGR}

\begin{abstract}
ABSTRAK
Abstrak: Program Daerah Pemberdayaan Gotong Royong (PDPGR). Program ini diharapkan mampu memberikan sebuah perubahan terhadap kehidupan masyarakat yang sudah dilaksanakan pada 57 desa sejak tahun 2016 dan salah satunya adalah Desa Kelanir Kecamatan Seteluk melalui kegiatan Pembangunan Jamban, Rehab Rumah Tidak Layak Huni (RTLH), Bariri Tani, Bariri Ternak, Pariri Lansia dan Pariri Disabilitas. Penelitian ini bertujuan untuk mendeskripsikan implementasi Peraturan Daerah Nomor 3 Tahun 2016 tentang PDPGR dan juga untuk menganalisis faktor yang mempengaruhi Strategi pemerintah dalam penerapan PDPGR di Desa Kelanir. Adapun metode yang digunakan dalam penelitian ini adalah kualitatif deskriptif dengan tehnik pengumpulan data melalui wawancara, observasi dan dokumentasi. Berdasarkan hasil penelitian menunjukkan bahwa secara umum Strategi PDPGR di Desa Kelanir mampu membangun kebersamaan dan meningkatkan kesejateraan dan perekonomian masyarakat setempat melalui kegiatan PDPGR, namun dalam pelaksanaanya dipengaruhi oleh banyak faktor seperti komunikasi, sumber daya, disposisi dan struktur birokrasi. PDPGR di Desa Kelanir tidak berjalan optimal dikarenakan tidak adanya sosialisasi program kepada masyarakat, rendahnya kaulitas agen Pemberdayaan PDPGR Desa Kelanir sebagai ujung tombak keberhasilan program serta tidak adanya Structure Operational Procedure (SOP) sejak tahun 2016 yang dijadikan pedoman pelaksanaan program.
\end{abstract}

\begin{abstract}
Regional Mutual Assistance Empowerment Program (PDPGR). This program is expected to be able to make changes to people's lives that have been implemented in 57 villages since 2016 and one of them is Kelanir Village, Seteluk District, Latrine Development, Rehabilitation of Unworthy Houses (RTLH), Bariri Tani, Bariri Livestock, Pariri Elderly and Pariri with Disabilities. This study aims to describe the implementation of Regional Regulation Number 3 of 2016 concerning PDPGR and also to analyze the factors affecting the government's strategy in implementing PDPGR in Kelanir Village. The method used in this research is descriptive qualitative by interviewing data through interviews, observation and documentation. Based on the results of the study, it shows that in general the PDPGR Strategy in Kelanir Village is able to build togetherness and improve the welfare and economy of the local community through PDPGR activities, but in its implementation it is based on many factors such as communication, resources, disposition and bureaucratic structure. PDPGR in Kelanir Village is not running optimally due to the absence of program socialization to the community, the low quality of the PDPGR Empowerment agent in Kelanir Village as the spearhead of the program and the absence of a Structure Operational Procedure (SOP) since 2016 which has been used as new program implementation.
\end{abstract}

\section{LATAR BELAKANG}

Kemiskinan sudah menjadi masalah global yang dialami oleh semua negara yang ada di dunia.
Kemiskinan tidak hanya berada dinegara-negara berkembang dan terbelakang, melainkan juga dialami oleh negara maju. Sepertiga penduduk di 
dunia masih hidup dalam kemiskinan dan hal tersebut sesuai dengan kriteria dari Bank Dunia bahwa klasifikasi masyarakat yang hidup dibawah garus kemiskinan adalah mneggunakan pendapatan per kapita sebesar US\$ Amerika sebagai tolah ukurna (Soelaman, 2006:228).

Saat ini pemerintah terus berupaya membuat suatu kebijakan yang dapat berpengaruh besar terhadap peningkatan kesejateraan sekaligus pengentasan kemiskinan, seperti halnya prgramprogram nasional yang sudha dilaksanakan di Indonesia yaitu Program Nasiona Pemberdayaan Masyarakat (PNPM), Onpres Desa Tertinggal (IDT), Bantuan Langsung Tunai (BLT), Beras untuk Masyarakat Miskin (Raskin), Kompensasi Bahan Bakar Minyak, Program Pengembangan Kecamatan (PKK), Program Penanggulangan Kemiskinan Perkotaan (P2K2), Program Keluarga Harapan (PKH) dan berbagai program lainnya dengan tujuan yang sama. Semua program yang dibuat oleh pemerintah bertujuan untuk meningkatkan dan kesejateraan dan mengurangi angka kemiskinan (Edhi,2017:15).

Begitu juga dengan pemerintah daerah Kabupaten Sumbawa Barat yang terdiri atas 9 Kecamatan, 7 Kelurahan dan 57 Desa yang beribu kota di Taliwang. Berdasarkan data Badan Pusat Statistik (BPS) Kabupaten Sumabwa Barat bahwa persentase kemiskinan di Kabupaten Sumbawa Barat pada tahun 2015 mencapai 16,97 \% atau dengan jumlah 22.500 jiwa (bpssumabwabarat.go.id). Dari masalah tersebut, Pemerintah Kabupaten Sumbawa Barat pada tahun 2016 menetapkan Peraturan Daerah Nomor 3 Tahun 2016 tentang Program Daerah Pemberdayaan Gotong Royong. Sebuah harapan dihadirkan oleh pemerintah untuk dapat meningkatkan kesejateraan masyarakat sekaligus mengentaskan kemiskinan. Peraturan Daerah lahir karena berbagai permasalahan yang terjadi serta semakin memudarnya budaya gotong royong dalam kehidupan masyarakat yang memberikan implikais negatif karena tidak adanya rasa kebersamaan dan partisipasi masyarakat.

Salah satu kegiatan Program Daerah Pemberdayaan Gotong Royong adalah Jambanisasi se-Kabupaten Sumbawa Barat. Berdasarkan data yang telah dihimpu agen pemberdayaan PDPGR sebanyak 7.027 rumah yang berhak untuk menerima bantuan pembuatan jamban se-KSB, namun setelah dilakukan verifikasi oleh Tim Pengerak tingkat Kecamatan ,maka tahun 2016-2017 jumlah rumah yang mendapat bantuan jambanisasi sebanyak 6.164 unit di seluruh KSB. Selain kegiatan jambanisasi, bedah rumah tidak layak huni juga menjadi salah satu kegiatan PDPGR. Tercatat tahun 2016 berhasil membedah rumah sebanyak 1.500 unit rumah dari target 6.300 unit rumah yang tersebar di seluruh desa di Sumbawa Barat (www.kabarntb.com). Berkaitan dengan pelaksanaan program di 57 desa yang tersebar di Sumbawa Barat, maka salah satu desa yang dimaksud adalah Desa Kelanir yang berada di wilayah Kecamatan Seteluk dengan 12 RT. Pelaksanaan PDPGR di Desa Kelanir sudah berjalan dan manfaatnya dirasakan oleh masyarakat sasaran program. Ketertarikan peneliti menentukan wilayah penelitian di Desa Kelanir karena desa ini karena merupakan salah satu desa dengan jumlah jamban yag sedikit serta jumlah rumah tidak layak huni yang banyak di wilayah Kecamatan Seteluk Kabupaten Sumbawa Barat.

Salah satu kegiatan yang dilakukan dalam program ini yaitu adanya kegiatan jambanisasi. hal ini dilakukan karena masih banyak masyarakat yang belum memilki jamban seperti halnya Desa Kelanir, dimana masyarakat yang menumpang jamban tetangga dan memanfaatkan sungai sebagai alternatif jamban yang sudah berlangsung lama yang menjaidkan masyarakat hidup secara tidak sehat. Selain itu, bentuk pelaksanaan dari program ini adalah bedah rumah tidak layak huni, pemberdayaan bakulan dan pemberdayaan petani serta bantuan lainnya yang sudah dilaksanakan di Desa Kelanir sejak tahun 2016 dan diharapkan mampu memberikan perubahan kesejateraan pada masyarakat dan mengentaskan kemiskinan. Dari berbagai harapan pemeirntah dan masyarakat dnegan keberadaaan PDPGR, peneliti ingin mengetahui sejauh mana implementasi program tersebut di Desa Kelanir.

Berdasarkan latar belakang di atas, maka masalah dalam penelitian ini, yaitu Bagaimana implementasi PDPGR terhadap pengentasan kemiskinan di Desa 
Kelanir dan apa yang akan menjadi faktor yang mempengaruhi implementasi PDPGR di Desa Kelanir

\section{TINJAUAN PUSTAKA}

Kebijakan Publik Menurut Dunn (1994) dalam (Dwiyanto, 2017) bahwa kebijakan publik lebih mudah dipahami jika dikaji tahap demi tahap. Inilah yang menjadi kebijakan publik penuh warna dan kajiannya amat dinamis. Berbicara mengenai proses kebijakan publik, William Dunn membagi tahap-tahap penyusunan kebijakan publik dengan urutan yang berbeda, yaitu : tahap penyusunan agenda, tahap formulasi kebijakan, tahap adopsi kebijakan, tahap implementasi kebijakan dan tahap evaluasi kebijakan.

Menurut Marrus (2002:31) strategi didefinisikan sebagai suatu proses penentuan rencana para pemimpin puncak yang berfokus pada tujuan jangka panjang organisasi, disertai penyusunan suatu cara atau upaya bagaimana agar tujuan tersebut dapat dicapai. Terdapat tiga faktor yang mempunyai pengaruh penting pada strategi yaitu:

1. Lingkungan eksternal

2. Sumber daya

3. Kemampuan internal serta tujuan yang akan dicapai

Artinya strategi adalah sebuah rencana yang telah disusun dengan memanfaatkan segala sumber daya serta peluang-peluang yang ada untuk mencapai tujuan organisasi. Selanjutnya, Strategi yang baik dan tepat memiliki proses yang lebih terperinci. mengusulkan tujuh aturan dasar dalam merumuskan suatu strategi sebagai berikut

a) Ia harus menjelaskan dan menginterpretasikan masa depan, tidak hanya masa sekarang.

b) Arahan strategi harus bisa menentukan rencana dan bukan sebal iknya.

c) Strategi harus berfokus pada keunggulan kompetitif, tidak sematamata pada pertimbangan keuangan. d) Ia harus diaplikasikan dari atas ke bawah, bukan dari bawah ke atas.

e) Strategi harus mempunyai orientas $i$ eksternal.

f) Fleksibilitas adalah sangat esensial.

g) Strategi harus berpusat pada hasil jangka panjang.

Untuk menjamin agar supaya strategi dapat berhasil baik dengan meyakinkan bukan saja dipercaya oleh orang lain, tetapi memang dapat dilaksanakan, Hatten dan hatten (1996: 108-109) memberikan beberapa petunjuknya sebagai berikut :

a) Strategi harus konsiten dengan lingkungan, strategi dibuat mengikuti arus perkembangan masyarakat, dalam lingkungan yang memberi peluang untuk bergerak maju.

b) Setiap organisasi tidak hanya membuat satu strategi, tergantung pada ruang lingkup kegiatannya.

Apabila ada banyak strategi yang dibuat maka strategi yang satu haruslah konsisten dengan strategi yang lain. Jangan bertentangan atau bertolak belakan, semua strategi senantiasa diserasikan satu dengan yang lain.

c) Strategi yang efektif hendaknya memfokuskan dan menyatukan semua sumber daya dan tidak mencerai beraikan satu dengan yang lain. Persaingan tidak sehat antara berbagai unit kerja dalam suatu organisasi sering kali mengklaim sumber dayanya, membiarkannya terpisah dari unit kerja lainnya sehingga kekuatankekuatan yang tidak menyatu itu justru merugikan posisi organisasi.

d) Strategi hendaknya memusatkan perhatian pada apa yang merupakan 
kekuatannya

dan tidak pada titik-titik yang justru adalah kelemahannya. Selain itu hendaknya juga memanfaatkan kelemahan pesaing dan membuat langkah-langkah yang tepat

untuk menempati posisi kompetitif yang lebih kuat.

e) Sumber daya adalah sesuatu yang kritis. Mengingat strategi adalah sesuatu yang mungkin, hendaknya dibuat sesuatu yang memang layak dapat dilaksanakan.

f) Strategi hendaknya memperhitungkan resiko yang tidak terlalu besar. Memang setiap strategi mengandung resiko, tetapi haruslah berhati-hati, sehingga tidak menjerumuskan organisasi kelubang yang lebih besar. Oleh karena itu strategi hendaknya selalu dapat dikontrol.

g) Strategi hendaknya disusun diatas landasan keberhasilan yang telah dicapai.

h) Tanda-tanda dari suksesnya strategi ditampakkan dengan adanya dukungan dar i

pihak-pihak yang terkait dari para eksekutif, dari semua pimpinan unit dalam organisas $i$

Strategi diformulasikan dengan baik akan membantu penyusunan dan pengalokasian sumber daya yang dimiliki perusahaan menjadi suatu bentuk yang unik dan dapat bertahan. Stategi yang baik disusun berdasarkan kemampuan internal dan kelemahan perusahaan, antisipasi perubahan dalam lingkungan, serta kesatuan pergerakan

Konsep Program Daerah Pemberdayaan Gotong Royong (PDPGR) Program Daerah Pemberdayaan Gotong Royong (PDPGR) adalah penyediaan ruang dan penegasan arah penguatan gotong royong sebagai suatu tata nilai dan cara mencapai tujuan yang dilaksanakan secara sukarela, bersama-sama dan tolong menolong dengan dilandasi semangat ikhlas, jujur dan sungguh-sungguh untuk mewujudkan pasrtisipasi, pemberdayaan dan perluasan kesempatan kerja masyarakat secara efesien, efektif dan produktif dalam rangka percepatan pengentasan kemiskinan (Peraturan Bupati Nomor 9 Tahun 2016 pasal 1 ayat 1 tentang Petunjuk Pelaksanaan PDPGR)

Konsep Pemberdayaan Masyarakat Menurut Zubaedi, (2013:4) menjelaskan bahwa pemberdayaan masyarakat muncul karena adanya suatu kondisi sosial ekonomi masyarakat yang rendah mengakibatkan mereka tidak mampu dan tidak tahu. Ketidakmampuan dan ketidaktahuan masyarakat inilah yang mengakibatkan produktivitas mereka rendah, sehingga ketika produktivitas masyarakat rendah maka tentu akan sangat berpengaruh kepada kualitas kehidupannya itu sendiri. Sehingga tidak heran jika pemebrdayaan masyarakat sangat dibutuhkan ketika kondisi seperti ini terjadi dalam kehidupan masyarakat. Disis lain menurut UNICEF dalam Sunyoto Usman (1998) mengajukan 4 dimensi sebagai tolak ukur keberhasilan pemberdayaan masyarakat yang tentunya keempat dimensi ini saling berhubungan satu sama lain, saling, saling menguatkan dan melengkapi, yaitu kesejateraan, akses, partisipasi dan kontrol.

\section{METODE PENELITIAN}

Dilihat dari obyek dan metode analisis yang digunakan, maka penelitian ini termasuk dalam jenis penelitian kualitatif yang menghasilkan data deskriptif mengenai kata-kata lisan maupun tertulis, dan tingkah laku yang dapat diamati dari orang yang diteliti dengan penjelasan secara terperinci tentang permasalahan yang berhubungan dengan teori yang ada dan medapat kesimpulan (Bagong Sunyoto, 2005:166). Penelitian ini juga menggunakan metode deskriptif yang berlokasi di Dinas Pemberdayaan Masyarakat dan Desa (DPMD) Sumbawa Barat dan di Desa Kelanir Kecamatan Seteluk Kabupaten Sumbawa Barat. Dimana dalam penelitian ini fokus pada pengamatan terhadap implementasi Peraturan Daerah Nomor 3 Tahun 2016 tentang PDPGR terhadap pengentasan kemiskinan di Desa Kelanir dan mengamati faktor apa saja yang mempengaruhi implementasi PDPGR di Desa Kelanir.Tehnik pengumpulan data dalam penelitian ini ada tiga yaitu wawancara, observasi dan dokumentasi dengan 
sumber data yang berasal dari data primer dan data sekunder.

\section{Pembahasan}

\section{Aspek Pemberdayaan Masyarakat}

Hasil penelitian tentang implementasi Peraturan Daerah Nomor 3 Tahun 2016 tentang Program Daerah Pemberdayaan Gotong Royong Terhadap Pengentasan Kemiskinan Studi Kasus di Desa Kelanir Kecamatan Seteluk pada Tahun 2016-2017, peneliti dapat menjelaskan beberapa poin penting dalam penelitian ini. Kebijakan tersebut merupakan program yang bertujuan untuk meningkatkan kesejateraan masyarakat dan mengentaskan kemiskinan melalui pemberdayaan gotong royong dan beberapa kegiatan lainnya, seperti pembangunan jamban, rehab rumah tidak layak hunis (RTLH), Pariri Disabilitas, Pariri Lansia, Bariri Tani dan Bariri UMKM. Pelaksanaan PDPGR di Desa Kelanir sejak tahun 2016 mampu meningkatkan kesejateraan masyarakat yaitu dari keluarga pra sejahtera menjadi keluarga sejahtera 1, dengan adanya peningkatan kesejateraan ini maka secara otomatis akan berpengaruh pada peningkatan kualitas hidup dan ketercukupan masyarakat. Perubahan yang dirasakan ini tentu didukung oleh adanya akses yang baik dalam hal ketersediaan sumber daya yang tercukupi baik itu sumber daya alam, ketersediaan implementator disetiap desa yang terdiri atas Tim Penggerak dan Agen Pemberdayaan PDPGR yang berjumlah 12 orang maupun anggaran yang dialokasi di Desa Kelanir yang mengalami peningkatan dari tahun 2016 ke 2017. Namun dalam tahap implementasi program tidak berjalan optimal karena tingkat partisipasi masyarakat Desa Kelanir yang masih rendah pada setiap kegiatan PDPGR yang mengakibatkan konsep program tidak singkron dengan fakta dilapangan.

"PDPGR mampu meningkatkan taraf kehidupan masyarakat karena dari semua kegiatan yang ada di PDPGR ini bertujuan untuk meningkatkan kesejateraan masyarakat, memperbaiki perekonomian serta percepatan pembangunan di Sumbawa Barat, seperti kegiatan Kartu Bariri, Kartu Pariri, Jambanisasi, serta Bedah dan Rehab Rumah Tidak Layak Huni

"Perbedaan dari tahun sebelumnya jelas ada, mula dari kualitas kesehatan masyarakat yang sekarang sudah bebas dari buang air besar sembarangan, para petani yang diberikan bantuan berupa alat tani, bibit, dan pupuk. Selain itu para lansia dan disabilitas yang diberdayakan melalui kartu Pariri serta adanya Bariri UMKM. Dan ini bukti nyata kegiatan yang dilakukan di Desa Kelanir ini mampu meningkatkan kesejahteraan sekaligus mengurangi angka kemiskinan"

Tabel 1.

Jumlah Sasaran Kegiatan PDPGR di Kabupaten Sumbawa Barat

\begin{tabular}{|c|c|c|}
\hline No & $\begin{array}{c}\text { Jenis Kegiatan DPPGR } \\
\text { KSB }\end{array}$ & Jumlah Sasaran \\
\hline 1 & Jambanisasi & 6.106 Unit \\
\hline 2 & Rehab RTLH & 2.536 Unit \\
\hline 3 & Bariri Tani & 6.800 Unit \\
\hline 4 & Bariri UMKM & 5.193 Orang \\
\hline 5 & Pariri Disabilitas & 766 Orang \\
\hline 6 & Pariri Lanjut Usia & 3.766 Orang \\
\hline & Total & $\mathbf{2 5 . 1 6 7 ~ S a s a r a n ~}$ \\
\hline
\end{tabular}

Sumber : Arsip Agen Peliuk Desa Kelanir Tahun 2017

Dilihat dari tabel 1 menggambarkan dengan jelas bahwa pelaksanaan PDPGR mampu memberikan perubahan pada kondisi masyarakat di Kabupaten Sumbawa Barat yang mengarah pada kesejahteraan hidup. Hal ini berdasarkan pada jumlah sasaran kegiatan PDPGR sejak tahun 2016 sampai tahun 2017 yang mencapai 25.167 sasaran dan mencakupi seluruh desa yang tersebar di Kabupaten Sumbawa Barat. Selain itu, Desa Kelanir sebagai lokasi penelitian yang sudah merasakan pengaruh terhadap tatanan kehidupan melalui beberapa kegiatan PDPGR sejak awal program dijalankan. Hal ini diperkuat dengan data pendukung yang relevan mengenai kesejateraan masyarakat Desa Kelanir, yaitu sebagai beirikut :

Tabel 2

Kesejahteraan Keluarga di Desa Kelanir 
Sumber : Arsip Agen Peliuk Desa Kelanir Tahun 2017

Dari table 2 diatas menjelaskan perbandingan tingkat kesejahteraan keluarga di Desa Kelanir pada tahun 2016 dan 2017. Keluarga prasejahtera merupakan sasaran atau target utama kegiatan PDPGR dengan memfokuskan pada peningkatan kesejateraan dan pengentasan kemiskinan. Program yang sudah direalisasikan sangat berpengaruh besar terhadap perbaikan kehidupan masyarakat khususnya Desa Kelanir, hal tersebut terlihat pada jumlah keluarga prasejahtera tahun 2016 mengalami penuruan yang signifikan pada tahun 2017 yaitu dari 193 menjadi 20 keluarga, sehingga dalam kurun waktu dua tahun terdapat 173 keluarga mengalami transformasi kehidupan layak melalui kegiatan PDPGR. Berdasarkan hasil penelitian, diperoleh informasi tentang jumlah penerima bantuan PDPGR Desa Kelanir tahun 2016 dan 2017.

Data tersebut dipertegas oleh hasil wawancara peneliti dengan informan yaitu Supiyanti (35 Tahun) selaku penerima bantuan dari kegiatan Rehab RTLH Tahun 2017 di desa Kelanir, menjelaskan :

"Kegiatan Rehab RTLH sangat membantu rumah kami yang sudah tidak layak huni, dalam pelaksanaannya kami tidak diberikan uang tunai namun dalam bentuk barang yang sudah dibelanjakan oleh agen untuk kegiatan rehab."

Disisi lain untuk untuk mengendalikan pelaksanaan program maka peran Pemerintah Kabupaten Sumbawa Barat dengan mewajibkan agen pemberdayaan PDPGR untuk membuat laporan secara berkala yaitu laporan kegiatan dan laporan akhir. Selain itu, Pemerintah Daerah membentuk tim khusus untuk memaksimalkan pengontrolan pelaksanaan program yaitu Tim Pengendalian dan Pengawasan PDPGR. Namun pengendalian yang dilakukan oleh masyarakat di Desa Kelanir maish tergolong rendah meskipun pemerintah daerah memberikan kesempatan penuh kepada masyarakat dalam mengontrol pelaksanaan PDPGR di masing-masing desa, hal ini menjadikan pelaksanaan PDPGR tidak optimal dalam hal pengendalian yang dilakukan oleh masyarakat.

\section{Peningkatan Kualitas Hidup}

Peningkatan kualitas hidup adalah perubahan yang diharapkan dapat tercapai setelah mengimplementasikan Peraturan Daerah Nomor 3
Tahun 2016 tentang PDPGR di Sumbawa Barat.

\begin{tabular}{|c|c|c|}
\hline $\begin{array}{c}\text { Kategori } \\
\text { Masyarakat }\end{array}$ & $\begin{array}{c}\text { Jumlah } \\
\text { /Keluarga }\end{array}$ & $\begin{array}{c}\text { Jumlah } \\
\text { /Keluarga } \\
\text { Tahun 2017 }\end{array}$ \\
\hline Prasejahtera & 193 keluarga & 20 Keluarga \\
\hline Sejahtera 1 & 287 keluarga & 464 Keluarga \\
\hline Sejahtera 2 & 0 keluarga & 0 Keluarga \\
\hline Sejahtera 3 & 0 keluarga & 0 Keluarga \\
\hline Sejahrera 3 plus & 0 keluarga & 0 Keluarga \\
\hline
\end{tabular}

Ketika masyarakat mengalami perubahan dalam kesejateraan maka hal ini akan berpengaruh terhadap peningkatan kualitas hidup masyarakat. Abbas HR (42 Tahun) selaku ketua agen desa mengungkapkan bahwa: "Secara umum masyarakat desa Kelanir bermata pencaharian sebagai petani dan pedagang. Sehingga ketika dikaitkan dengan kegiatan PDPGR, maka masyarakat yang berprofesi sebagai petani dan pedagang tersebut akan sangat terbantu dengan adanya bantuan-bantuan sosial yang diberikan oleh Pemerintah Daerah melalui Bariri Tani dan Bariri UMKM."

Berdasarkan pernyataan diatas, dijelaskan bahwa pelaksanaan PDPGR di Desa Kelanir akan berpengaruh pada peningkatan kualitas hidup masyarakat ketika hal tersebut dihubungkan dengan mata pencaharian pokok masyarakat Desa Kelanir yang secara umum didominasi oleh petani dan pedagang kecil, sehingga melalui kegiatan PDPGR seperti Bariri Tani dan UMKM yang dilaksanakan sejak tahun 2017.

Pernyataan diatas senda dengan pendapat yang disampaikan oleh Ibrahim Saleh (51 Tahun) selaku penerima bantuan Bariri Tani, menjelaskan :"Setelah adanya program Bariri Tani, saya dan petani kecil yang ada di desa Kelanir sangat terbantu dengan adanya pemberian pupuk urea,bibit padi dan bibit jagung hanya dengan menabung $10 \%$ ditahap awal di bank NTB. Dengan bantuan tersebut kami para petani akan semakin termotivasi untuk meningkatkan hasil produksi padi dan jagung."

Pembangunan jamban sebagai salah satu kegiatan PDPGR yang sudah direalisasikan sejak tahun 2016, dalam pelaksanaan program dengan kurun waktu dua tahun sudah memperoleh 372 kelompok sasaran. Berkaitan dengan kegiatan pembanguan jamban, salah satu informan yaitu Samsi Darto (39 Tahun) selaku Ketua agen Peliuk Desa Kelanir, menjelaskan :"Pembangunan jamban 
di desa Kelanir sejak tahun 2016 sampai peningkatann kualitas jamban pada tahun 2017 sangat berpengaruh terhadap kualitas kesehatan masyarakat, jika sebelum adanya program ini banyak keluarga yang tidak memiliki WC disetiap rumah dan ada beberapa keluarga dengan kondisi WC yang tidak layak pakai tetapi masih digunakan. Namun setelah program ini direalisasikan, permasalahan tersebut bisa diatasi."

Untuk memperbaiki kehidupan masyarakat maka salah satu ikhtiar yang ditempuh oleh pemerintah daerah yaitu melalui bidang kesehatan serta pola hidup bersih dan sehat masyarakat. Sehingga hal tersebut diwujudkan dalam bentuk kegiatan pembangunan jamban yang memperioritaskan keluarga prasejahtera sebagai kelompok sasaran di Desa Kelanir sejak tahun 2016 sampai tahun 2017. Adapun hasil wawancara peneliti dengan salah satu informan yang mendapat bantuan pembangunan jamban tahun 2016 yaitu Dedi Susanto (30 Tahun) menjelaskan :"Bantuan pembangunan jamban sangat diperlukan oleh masyarakat atau keluarga di desa Kelanir yang tidak memiliki jamban seperti saya. Karena jamban merupakan salah satu kebutuhan dasar yang harus dipenuhi. Oleh sebab itu, ketika pembangunan jamban ini dilaksanakan maka hal ini akan mempengaruhi kualitsa kesehatan masyarakat tersebut."

Tabel 3

Ketersediaan Anggaran PDPGR

\begin{tabular}{|l|l|c|}
\hline No & $\begin{array}{c}\text { Jenis Kegiatan } \\
\text { PDPGR }\end{array}$ & Ketersediaan Dana dan Sumber \\
\hline 1 & Jambanisasi & $\begin{array}{c}\bullet \text { Rp.10.244.000.000 (APBD } \\
\text { dan APBDes) Tahun 2016 } \\
\text { Rp. 18.000.000.000 (APBN) } \\
\text { Tahun 2017 }\end{array}$ \\
\hline 2 & Rehab RTLH & $\begin{array}{c}\text { Rp.10.200.000.000 (APBD } \\
\text { dan APDes) Tahun 2016 } \\
11.480 .000 .000 \text { (APBN dan } \\
\text { CSR) Tahun 2017 }\end{array}$ \\
\hline 3 & Pariri Lansia dan & $\begin{array}{c}\bullet \text { Rp. 13.335.750.000 (APBD } \\
\text { dan APBDes) Tahun 2017 }\end{array}$ \\
\hline 4 & Disabilitas & $\begin{array}{c}\text { Rp. 20.000.000.000 (APBD) } \\
\text { Tahun 2017 }\end{array}$ \\
\hline 5 & Bariri UMKM & $\begin{array}{c}\bullet \text { Rp. 10.336.263.000 (APBD) } \\
\text { Tahun 2017 }\end{array}$ \\
\hline
\end{tabular}

Sumber : Arsip Agen Peliuk Desa Kelanir Tahun 2017

Berdasarkan tabel diatas, peneliti memberikan pendapat bahwa pelaksanaan PDPGR di Kabupaten
Sumbawa Barat memiliki ketersediaan sumber daya dalam bentuk anggaran yang tidak hanya berorientasi pada APBD sebagai sumber utama, akan tetapi sejak tahun 2016 kontribusi APBDes, Perusahaan atau CSR bahkan APBN dalam bentuk dana hibah sudah memberikan hasil dan dampak dalam transformasi kehidupan masyarakat Sumbawa Barat.

Selain itu berdasarkan hasil peneliti menunjukan ketersediaan anggaran kegiatan PDPGR di desa Kelanir pada tahun 2016 dan 2017. Data tersebut dituangkan dalam tabel berikut :

\section{Tabel 4}

Ketersediaan Anggaran dalam Pelaksanaan PDPGR

\begin{tabular}{|c|c|c|}
\hline Tahun & Jumlah Anggaran & Jumlah Sasaran \\
\hline 2016 & 273.500 .000 & 156 sasaran \\
\hline 2017 & 338.300 .000 & 216 sasaran \\
\hline
\end{tabular}

Sumber : Arsip Agen Peliuk Desa Kelanir Tahun 2017

Menurut tabel 4 diatas mengungkapkan bahwa ketersediaan anggaran dalam pelaksanaan PDPGR di Desa Kelanir mengalami peningkatan yang signifikan seiring dengan bertambahnya jenis kegiatan yang diselenggarakan pada tahun 2017 dan tentunya berpengaruh pada jumlah kelompok sasaran dari masing-masing kegiatan. Munculnya kegiatan baru, menjadikan pemerintah daerah juga harus siap dengan penyediaan anggaran untuk menjamin program tersebut dapat direalisasikan dalam kehidupan masyarakat dan tidak hanya angan-angan semata.

Beberapa data yang diperoleh, peneliti menganalisa bahwa ketersediaan sumber daya dalam pelaksanaan PDPGR di Desa Kelanir telah tercukupi. Hal tersebut ditinjau dari sumber daya manusia (SDM) yaitu penentuan jumlah implementator yang dikerahkan dalam penyelenggaraan kegiatan, sumber daya alam (SDA) kaitannya dengan kondisi alam di Desa Kelanir yang sudah sesuai dengan kegiatan yang diselenggarakan, maupun kesiapan anggaran oleh pemerintah daerah sudah memenuhi jumlah kelompok sasaran yang diajukan oleh agen Pemberdayaan Desa Kelanir.

\section{SIMPULAN DAN SARAN}


Implementasi Program Daerah Pemberdayaan Gotong Royong khususnya di Desa Kelanir telah memberikan pengaruh terhadap peningkatan kesejateraan masyarakat dan mengurangi angka kemiskinan meskipun belum dalam mampu mnegentaskan kemiskinan dalam skala besar. Adanya perubahan ini dilatar belakangi oleh beberapa kegiatan PDPGR seperti pembangunan jamban, rehab rumah tidak layak huni, Bariri UMKM, Bariri Tani, Pariri Lansia dan Pariri Disabilitas yang sudah dilaksanakan sejak tahun 2016 dengan konsep pemberdayaan gotong royong.

Faktor yang mempengaruhi implementasi Peraturan Daerah Nomor 3 Tahun 2016 tentang Program Daerah Pemberdayaan Gotong Royong terhadap pengentasan kemiskinan di Desa Kelanir adalah adanya variabel komunikasi, sumber daya, disposisi dan struktur birokrasi. Namun dalam pelaksanaan program tidak berjalan optimal karena tidak adanya sosialisasi program pada masyarakat, rendahnya kualitas agen Pemberdayaan Desa Kelanir serta tidak adanya Structure Operational Procedure (SOP).

Pemerintah Daerah khususnya pemangku kepentingan seharusnya melakukan sosialisasi secara berkala dengan tujuan masyarakat sebagai penerima bantuan dapat memahami dengan jelas program yang sedang dijalankan.. Selain itu, untuk meningkatkan keefektifan pelaksanaan PDPGR maka penyelenggara program seharusnya menyegerakan penyusunan SOP sebagai pedoman yang mampu mengarahkan setiap kegiatan PDPGR.

Agen Pemberdayaan Desa dan Agen Peliuk Desa Kelanir seharusnya lebih genjar dalam menggerakkan masyarakat untuk melibatkan diri dalam setiap kegiatan PDPGR agar konsep gotong royong yang dicita-citakan dapat singkron dengan aktualisasi dilapangan.

Agen Pemberdayaan PDPGR sebagai garda terdepan dalam pelaksanaan program sangat membutuhkan pelatihan dan pembinaan begitupan dengan agen diDesa Kelanir, mengingat masih rendahnya Sumber Daya Manusia (SDM) yang ditersedia oleh masing-masing agen.

Bagi masyarakat di Kabupaten Sumbawa Barat, khususnya di Desa Kelanir agar lebih aktif berpartisipasi dalam semua kegiatan PDPGR sebagai bentuk dukungan terhadap program daerah yang sedang di implementasikan dan tujuan pemberdayaan gotong royong dari program ini dapat terwujud.

\section{UCAPAN TERIMA KASIH}

Penulis mengucapkan terima kasih kepada semua pihak yang memberikan usul, saran dan senantiasa memberikan bimbingan, nasehat, dan motivasi kepada penulis sehingga penelitian ini selesai dengan baik.

\section{DAFTAR RUJUKAN}

Bohnsack, R., \& Przyborski, A. (2010). Diskursorganisation, Gesprächsanalyse und die Methode der Gruppendiskussion. Das Gruppendiskussionsverfahren in der Forschungspraxis, 2, 233-248.

Hatten, K J. and Hatten, M. L 1996. " Strategic Groups, Asymmetrical Mobility Barriers, and Contestbility," Strategic Management Journal. United States of America:Elsevier Inc

Hasfi, N., Usman, S., \& Hedi Pudjo, S. DEMOKRASI DIGITAL DALAM MEDIA SOSIAL (Representasi Jokowi-Prabowo dalam Kontestasi Pemilu Presiden 2014 di Twitter).(2017a). Laporan Disertasi diunduh dari www. lib. ugm. ac. id.

Goldworthy dan Ashley. Australian Public Affairs Informtion Service. Australia :APAIS, 1998.

Indihono, Dwiyanto. 2017. Kebiijakan Publik Berbasis Dynamic Policy Analisys. Yogyakarta:GAVA MEDIA.

Martono,Edhi. Pemberdayaan Masyarakat Melalui Pengembangan Desa Wisata dan Implikasinya Terhadap Ketahanan Sosial Budaya Wilayah (Studi di Desa Wisata Penglipuran Bali). Vol.23.No.1, 27 April 2017 Hal.1-16 diakses pada Jumat, 19 Oktober 2018 pukul 19:20 WITA.

Marrus, Stephanie. 2002. Building The Strategic Plan: Find Analyze, And PresentThe Right Information. Wiley. USA.

Soelaman. 2006. Pemberdayan Masyarakat dalam Bidang Ekonomi:Tinjauan Teoritik dan Implementasi. Jakarta : Seminar Sehari Pemberdayaan Masyarakat : Bappenas.

Suharno. 2013. Dasar-Dasar Kebijakan Publik Kajian Proses Dan Analisis Kebijakan. Yogyakarta : Ombak Dua.

Nashar, N. (2018). WAJAH MASJID DI MADURA (Studi Historis Dan Sosiologis Dinamika Manajemen Masjid dalam Pemberdayaan Ummat). NUANSA: Jurnal Penelitian Ilmu Sosial dan Keagamaan Islam, 15(2), 333-364.

Zubaedi. 2013. Pengembangan Masyarakat Wacana dan Praktik. Jakarta : PT. Fajar Interpratama Mandiri. 